\title{
Die kerk se pastorale taak ten opsigte van die moderne stadsmens*
}

\author{
JPJ WAGENAAR
}

\section{DIE MODERNE STADSMENS}

'n Internasionaal-bekende denker en skrywer oor die kerk in die grootstadsituasie, Francis Schaeffer, het een van sy boeke oor hierdie onderwerp, die volgende titel gegee: Death in the city. Daarin spreek hy sy kommer uit omdat die dood in die stad gekom het en dat die moderne stad leeg en koud geword het. Hy verwys daarmee na die leegheid en die koudheid wat daar in die hart van die moderne stadsmens gekom het - 'n wegbeweeg van die warmte van die gemeenskap met God en die gemeenskap van die heiliges. Daarom sê hy dat die dood in die stad gekom het.

Ons moet egter nie dink dat ons besorgdheid oor die kerk in die stad 'n nuwe soort kommer is nie. In die geskiedenis-navorsingsprojek van die R.A.U. onder die titel: "Afrikaners in die Goudstad (Deel 1)", sien ons dat hierdie kommer in ons land oor die kerk in die stad, reeds bykans ' $n$ eeu oud is. As voorbeeld word een paragraaf uit hierdie projek aangehaal: "Die verstedeliking van die Afrikaner het egter'n geleidelike verandering in sy maatskaplike en godsdienstige lewe teweeggebring. Sedert 1895 is daar dikwels in die gemeenteverslae gekla oor die afname van die invloed van die kerk op die lidmate soos wat dit uit die swak bywoning van die eredienste geblyk het. In die stedelike samelewing het die Afrikaners met verskillende invloede in aanraking gekom wat nie altyd ' $n$ goeie uitwerking op hulle gehad het nie." Verskeie voorbeelde van die invloed van verstedeliking op die drie Afrikaanse susterkerke word dan genoem. Ter illustrasie noem ons 'n paar: swak kerkbesoek; die feit dat die lidmate 'n vlottende en trekkende groep mense geword het; drankmisbruik; loterye en weddenskappe op resiesperde; miskenning van die Sondag; prostitusie en verskeie ander euwels. Sodanig was die kerk hieroor besorg dat een gemeente in 'n ringsverslag van 1896 geskryf het: "de onzedelykheid staat als een monster op in deze groote wereldstad", terwyl prof NJ Hofmeyer na 'n besoek aan Johannesburg in 1896 gewaarsku het dat "zy maakt een bezoek te Johannesburg voor de onvasten gevaarlijk".

Ons sou hierdie lys van euwels waarmee die kerk bykans honderd jaar gelede in die stadsituasie te make gehad het, vandag sekerlik

* Referaat gelewer tydens 'n byeenkoms Kerk en Universiteit by die Randse Afrikaanse Universiteit. 
veel langer kan maak. Ons sou talle misstande kan bynoem wat tipiese verskynsels van die moderne samelewing is - veral in die stad. Ons identifiseer dan slegs ' $n$ paar: die ontstaan van sub-kulture en kultusse (veral onder jongmense); die misbruik van dwelmmiddels; die uitbuiting van die seksuele; homoseksualisme; die verbrokkeling van die huwelik en die huisgesin; die gejaag na aardse besittings en genietinge en nog vele ander.

Vir die kerk om sy pastorale taak te volvoer, is dit belangrik om van hierdie feitelike situasie kennis te neem. Belangriker as hierdie tipiese verskynsels van die moderne grootstad, is die feit dat daar na die oorsake van hierdie verskynsels gesoek moet word. Wanneer na die ware oorsake gesoek word, word dit moontlik vir die kerk om die stad nie as ' $n$ bedreiging nie, maar as 'n geleentheid, ' $n$ uitdaging te sien. Dit word moontlik wanneer die kerk sal begryp dat die ware stryd nie lê teen die stad waarin die mens lewe nie, maar eerder soos DJ Louw dit stel in sy boek getiteld: Die stad in die mens. Louw stel dit dat die stad ' $n$ toestand is in die hart van die twintigste-eeuse mens. 'n Ander skrywer oor hierdie onderwerp - PJ Jordaan - praat van die stad as ' $n$ "state of mind, a way of behaving".

Wanneer ons dan soek na die oorsake wat hierdie "stad in die mens" tot gevolg gehad het, is daar 'n groot aantal wat gewis identifiseerbaar is en waarvan die kerk kennis moet neem. Kom ons kyk kortliks na slegs 'n paar daarvan:

\subsection{Massafikasie}

Omdat so 'n groot aantal mense oor die hele wêreld stadsmense geword het, het ons vandag te doen met die massa-mens en al die implikasies daarvan. In 1820 het slegs twee stede in die wêreld 'n bevolking van meer as ' $n$ miljoen inwoners gehad. In 1900 was daar 10 sulke stede; in 1950 75; terwyl daar na verwagting in 1985270 sulke stede sal wees en 17 met meer as 10 miljoen inwoners. Hierdie wêreldtendens van verstedeliking, beleef ons ook in Suid-Afrika. In die massa gebeur dit dikwels dat die enkeling verdwerg en gedepersonaliseer word. Tussen die skares van die stad, is daar vandag baie eensame mense. In 'n studie wat in 'n Amerikaanse stad uitgevoer is, is vasgestel dat getroude middelklas-egpare, gemiddeld slegs met sewe eenhede (enkeling of paar) bevriend is. Hoewel stadsmense naby mekaar woon, raak hulle innerlik meer en meer van mekaar verwyderd. In ' $n$ onbetrokkenheid by ander en op ' $n$ bykans identiteitslose wyse, leef baie mense in 'n groot stad maar in 'n klein wêreldjie. Vir baie is dit dikwels ' $n$ traumatiese ervaring en word ontvlugting gesoek in een of meer van die genoemde euwels wat tipies van die grootstad is. Met hierdie anonimiteit van die stadsmens moet die kerk in sy pastorale werk rekening hou maar ook 
daarmee as 'n gegewendheid in die stad rekening hou en dit selfs aan die mense gun wat dit verkies en kan verwerk. Om die mens in 'n kunsmatige gemeenskap in te forseer, het dikwels geen sin of betekenis nie.

\subsection{Gebrek aan kommunikasie}

Die kommunikasiegaping wat baie raakpunte met die massafikasie het, is sekerlik een van die grootste oorsake van baie probleme van die moderne mens. Hierdie kommunikasiegaping bestaan in verskillende verhoudinge van mense: man en vrou; ouers en kinders; werkgewer en werknemer; ampsdraers en lidmate; politici en kiesers en op vele ander terreine. Vele faktore veroorsaak hierdie gapings. Ons noem slegs enkeles:

- In hierdie koue, onpersoonlike wêreld verkies die massamens om nie sy probleme met ander (selfs met die predikant) te bespreek nie.

- Vaders (en dikwels ook moeders) het in die stad pendelaars geword tussen woonplek en werkplek. Die tyd wat by die woonplek deurgebring word, weens die hoë eise van die beroepslewe, is dikwels ontoereikend vir sinvolle kommunikasie in die huisgesin.

- Televisie-kyk het die plek van kommunikasie in huisgesinne en tussen mense in wyer verband, ingeneem. Hierdie is 'n wêreldwye probleem. 'n Amerikaanse ondersoek het byvoorbeeld aangetoon dat ' $n$ kind onder 5 jaar gemiddeld 23 uur per week televisie kyk en teen die tyd dat sy hoërskoolloopbaan voltooi is, 15-duisend uur voor die televisie deurgebring het en teen dié tyd 350duisend advertensies en 18-duisend moorde gesien het.

Dat kommunikasiegapings om genoemde en verskeie ander redes, 'n geweldige invloed op die moderne mens het, is onbetwisbaar waar. Ons noem slegs een voorbeeld: 'n onlangse ondersoek by tehuise vir ongehude moeders het aangetoon dat in verreweg die meeste gevalle daar ' $n$ ernstige kommunikasieprobleem tussen die betrokkenes en hulle ouers was.

\subsection{Die "vryheid" van die mens}

Die sogenaamde vryheid van die individu is in die moderne vrye wêreld bykans tot godsdiens verhef. Veral in die VSA sien mens dikwels selfs absurde konsekwensies hiervan. Hiermee word bedoel die eis van die moderne mens dat hy mondig is, dat hy vry is om met sy lewe te maak wat hy wil. Oor sy eie doen en late wil hy aan niemand verantwoording verskuldig wees nie. Hierdie eis het uiteraard verreikende implikasies vir die verskillende gesagstrukture van 
die samelewing. Die onderwerping in gehoorsaamheid aan die Woord van God en die opsig en toesig van die kerk word hierdeur geraak. Die onderwerping aan die gesag van die staat, die ouers en die owerhede van verskillende gesagstrukture kom hierdeur in gedrang. 'n Belangrike gevolg van hierdie vryheidseis van die mens in die moderne stadsgemeenskap, is dat die mens al meer vrymoedigheid kry om selfs op blatante wyse te leef na sy eie sin en wil. Voorbeelde hiervan is talryk:

- Al verbied die wet van die Here egbreuk, is egbreuk al in so 'n mate deur die gemeenskap gesanksioneer dat dit as normaal aanvaar word.

- Die saamwoon van ongetroudes en buite-huwelikse geslagsgemeenskap vind op ontstellend groot skaal plaas, onder andere weens die feit dat dit in boeke, tydskrifte, films en oor televisie as normale praktyk voorgestel word.

- Homoseksualisme neem skynbaar toe, maar waarskynlik het hulle slegs groter vryheid en vrymoedigheid om dit bekend te laat word.

- Meer en meer mense verklaar blatant dat hulle aan geen God glo nie en geen deel aan die kerk wil hê nie. Daarom praat 'n sekere skrywer al van die Christene van die moderne stad as "Christians by decision", terwyl die Christene van die platteland, "Christians by accident" genoem word. Die moderne mens neem steeds meer die vrymoedigheid om "nee" te sê vir God en sy Woord en sy kerk.

Met hierdie genoemde oorsake volstaan ons, al sou talle ander invloede genoem kan word, soos snelle verandering of toekomsskok, industrialisasie en outomatisasie, ekonomiese ontwikkeling en welvaart, defaitisme en talle ander.

\section{DIE KERK SE PASTORALE TAAK MET HIERDIE STADSMENS}

Uit die aard van die saak is dit onmoontlik om binne hierdie bestek al die aspekte van die pastorale taak van die kerk met die moderne stadsmens te bespreek. Hier kan hoostens 'n paar riglyne getrek en moontlikhede bespreek word.

\subsection{Meer doeltreffende benutting van bestaande kerklike strukture}

\subsubsection{Die wykstelsel}

Die wykstelsel wat in ons kerke bestaan is 'n uitstekende stelsel, 
mits dit na behore benut word. Dit kom daarop neer dat ons hele land in selle onderverdeel is. Iemand kan by bykans enige adres in die ganse Suid-Afrika woon en onmiddellik kan ons vasstel dat so 'n persoon in ' $n$ besondere gemeente van een van ons kerke ressorteer en meer nog, dat so 'n persoon deel van 'n sekere wyk is saam met 'n paar ander gesinne en dat daar ' $n$ ouderling en diaken is om hulle ampswerk by daardie besondere huis te verrig. Teoreties lyk dit na 'n perfekte sisteem en is dit te betwyfel of enige ander land dit kan sê! Al wat kortkom is dat ons hierdie sisteem nie na behore benut nie.

\subsubsection{Die ouderling en die wykstelsel}

Ten einde die wykstelsel behoorlik te benut, is dit dringend noodsaaklik dat die amp van ouderling tot sy volle reg moet kom. By baie kerke in die buiteland het die wyksouderling in onbruik geraak en is die kerke bereid om bloot voort te gaan met die meelewende lidmate wat uit eie beweging by die kerk aanmeld. Nie alleen vir die pastorale taak van die kerk nie, maar ook vir die taak van evangelisasie in hierdie tyd van toenemende buitekerklikheid, kan die ouderling 'n uiters belangrike rol vervul. ' $n$ Belangrike voorvereiste is egter dat die ouderlinge vir hulle taak toegerus moet wees. Daarom sal daar baie meer daaraan aandag gegee moet word om die ouderlinge vir hulle ampswerk toe te rus. Bereidwilligheid en entoesiasme is eenvoudig nie meer genoeg nie!

\subsubsection{Die diaken en die wykstelsel}

In die formulier vir die bevestiging van diakens word die volgende van die amp van diaken gesê: "Daarom is dit goed dat hulle nie net met die uiterlike gawes nie, maar ook met gepaste trooswoorde uit die Woord van God, aan die armes en ellendiges hulp verleen." Dat hierdie woorde in die praktyk werklikheid moet word, is dringend noodsaaklik. Ons durf eenvoudig nie van die diaken 'n kollektant maak nie. Tydens sy gereelde maandelikse besoeke kan die diaken die lidmate in sy wyk beter leer ken as wat die ander ampsdraers hulle ken. Daarom kan hy ook van hulle nood, ellende, eensaamheid en beproewing kennis neem en die diens van barmhartigheid aan hulle bewys. Met slegs enkele verdere opmerkings oor die diakonaat word volstaan:

\section{- Toerusting}

Om bloot ' $n$ kollektant te wees, is redelik maklik en nie veel toerusting is nodig nie. Om egter sinvol diaken te wees, is veel moeiliker. Daarom sal daar aan die toerusting van die diakens dringend en volgehoue aandag gegee moet word. 
- Die vrou in die amp

By die werklike barmhartigheidsdiens deur die amp van die diaken kan die diakones ' $n$ belangrike funksie vervul. Daar is talle vroue wat kundiges is en andere wat goed toegerus is ten einde sinvolle barmhartigheidsdiens as diakonesse te verrig. Hiervan kan veel beter gebruik gemaak word.

- Die ouderdom van die diaken

Tradisioneel word die jongmense in die Kerk as diakens gekies en die oueres as ouderlinge. Dit behoort nie 'n standaard-praktyk te wees nie. Ten einde werklik die diens van barmhartigheid aan die moderne stadsmens te bewys, kan meer ervare en toegeruste persone ' $n$ belangrike rol vervul as diakens in die gemeente.

\subsubsection{Die predikant en huisbesoek}

Huidiglik bestaan die gebruik dat die predikant by al die lidmate sistematies huisbesoek doen om sodra hy klaar is, onmiddellik weer voor te begin. Wie objektief na hierdie werkwyse kyk, sou daaruit die afleiding kan maak dat al die lidmate in die gemeente die pastorale gesprek van die predikant ewe nodig het. Dit is tog immers nie die geval nie! Het dit dan nie tyd geword dat hierdie werkwyse bevraagteken word nie? Om een alternatiewe werkwyse voor te stel: Die predikant kan elke tweede jaar poog om by die hele gemeente besoek af te lê. In die jaar tussenin, in samewerking met die wyksouderling, kan probleemgevalle geïdentifiseer word en slegs dáár besoek afgelê word. Dan kan daar tyd wees vir noodsaaklike opvolgwerk en vir die toerusting van die ander ampsdraers.

\subsection{Belangegroepe benewens wyksgroepering}

In sy boek: "Die daad by die woord", noem prof HJC Pieterse die interessante moontlikheid om van interesse-groepe in die gemeente gebruik te maak. Daar is al dikwels in die kerk gepoog om die lidmate van ' $n$ bepaalde wyk in ' $n$ groep byeen te bring ter wille van hulle toerusting, maar ook ter wille van die sosiale verkeer waartydens hulle mekaar beter kan leer ken. Dit funksioneer wel goed in sommige gevalle. Die feit is dat in dieselfde wyk mense van verskillende belangstellings, beroepe, geaardhede en voorkeure is. Die gedagte is dan om belangegroepe daar te stel van mense met dieselfde beroep of ook weens ' $n$ ander saambindende rede, soos ouderdom, geslag, belangstellings, ensovoorts. Sulke geleenthede waar van die ampsdraers teenwoordig kan wees en waarvan die kerkraad terugvoering kry, word dan gebuik om gelowiges binne ' $n$ bepaalde groep beter toe te rus vir hulle dienswerk in die wêreld. 


\subsection{Gebruikmaking van kundiges ter wille van voorkomingsdienste}

Baie is reeds gesê oor die talle euwels, versoekinge en vraagstukke waarmee die kerk in die moderne stad te make het. Die kerk moet nie net bloot aan die probleme aandag gee nie, maar gewis ook aan die voorkoming daarvan. Hiervoor kan goedskiks gebruik gemaak word van die talle deskundiges op verskillende terreine wat lidmate van die Kerk is. Ons is bewus daarvan dat dit reeds op' $n$ klein skaal plaasvind maar is tog nog van mening dat dit verder uitgebou kan word. Verskillende gemeentes en kerke kan in hierdie verband saamwerk en 'n kosbare diens lewer. Só byvoorbeeld kan kursusse of seminare aangebied word vir verloofdes, met die oog op huweliksverryking, as voorligting aan jeuggroepe, oor kinderleiding, voorbereiding vir aftrede en talle ander.

\subsection{Samewerking tussen susterkerke}

Daar word dikwels menings uitgespreek en besprekings gevoer oor die moontlike eenwording van die Afrikaanse susterkerke. Terwyl hierdie gesprekke - formeel en informeel - dan aangaan, hoef formele eenwording sekerlik nie eers werklikheid te word, voordat daar op verskillende terreine baie beter saamgewerk word nie. In die stad is daar talle geleenthede daarvoor en veroorsaak onafhanklike en oorvleuelende werk dikwels 'n vermorsing van arbeidkrag. Die genoemde belangegroepe en die gebruikmaking van kundiges vir toerusting, kan sekerlik oor kerkgrense heen strek. Die doen van kerksensus kan veel vinniger en teen baie minder koste gedoen word as dit gesamentlik aangepak sou word. Hierdie is slegs enkele voorbeelde, maar natuurlik is daar nog vele ander gemeenskaplike sake in diens van die koninkryk van God.

\section{GOD}

Dit is duidelik dat daar hoë eise gestel word aan die kerk in die moderne stad, maar ook dat daar nuwe opwindende uitdagings en geleenthede vir die kerk is. As 'n mens samevattend wil sê hoe die kerk in die moderne stad by die moderne mens sy taak sien, dan is dit opvallend dat veral Amerikaanse teoloë - wat al baie oor hierdie onderwerp nagevors en geskryf het - verskillende modelle voorstel. 'n Interessante en aanvaarbare model is dié van John S. Reist wat in 'n vaktydskrif van die National Institute for Campus Ministries dit stel dat die kerk sy taak met die moderne mens as drie elemente moet sien, wat nie in volgorde nie maar altyd gesamentlik teenwoordig moet wees: 


\subsection{Kerugmatiese teenwoordigheid}

Dit hou in dat onbeskaamd en sonder kompromie geproklameer of verkondig moet word: "So spreek die Here!" Die eise van die woord van die Here is nie veranderbaar om by die sieninge van die moderne mens te pas nie.

\subsection{Terapeutiese teenwoordigheid}

Dit beteken dat die kerk moet dien tot sorg en bystand aan die moderne mens met sy besondere beproewinge en eietydse probleemsituasies.

\subsection{Didakties-skeppende teenwoordigheid}

Hiermee word bedoel dat die kerk ook na die moderne mens moet luister, ja - selfs na die verwronge oortuigings wat die moderne stadslewe by baie mense teweegbring. Deur die pastorale gespreksvoering kan daarvandaan skeppend gewerk word om nuwe waardes en oortuigings te vestig, wat na die eis van God se woord is.

Die kerk in die stad het 'n geweldige taak. Voortdurend sal nuwe eise aan die kerk gestel word tot op die dag dat die woorde van Johannes in Openbaring waar word, waar hy skryf oor die nuwe Jerusalem: "'n Tempel het ek nie in die stad gesien nie." In daardie stad sal nie 'n kerk wees nie, want dan is die stad kerk.

\section{Geraadpleegde bronne}

Greenway, Roger S. - Disciplining the City.

Schaeffer, Francis A. - The Church at the end of the 20th Century.

Louw, D.J. - Die stad in die mens.

Pieterse, H.J.C. - Die daad by die Woord.

The N.I.C.M. Journal. - Fall 1980.

Toffler, Alvin. - Future Shock.

Armstrong, $\mathrm{H}$. - The wonderful world of tomorrow.

Pretorius, J.W.M. - Opvoeding, samelewing, jeug.

Schaeffer, Francis. - Death in the City.

Fisher, Tadd. - Our overcrowded world.

Deel 1 - Afrikaners in die Goudstad. 